Review Article

\title{
Soluble Lectin-Like Oxidized Low Density Lipoprotein Receptor-1 as a Biochemical Marker for Atherosclerosis-Related Diseases
}

\author{
Angela Pirillo ${ }^{1,2}$ and Alberico Luigi Catapano ${ }^{1,3}$ \\ ${ }^{1}$ Center for the Study of Atherosclerosis, Bassini Hospital, Via Gorki 50, Cinisello Balsamo, 20092, Italy \\ ${ }^{2}$ IRCCS MultiMedica, Via San Barnaba 29, 20162 Milan, Italy \\ ${ }^{3}$ Department of Pharmacological and Biomolecular Sciences, Università degli Studi di Milano, Via Balzaretti 9, 20133 Milan, Italy
}

Correspondence should be addressed to Angela Pirillo; angela.pirillo@guest.unimi.it

Received 27 June 2013; Accepted 26 August 2013

Academic Editor: Serge Masson

Copyright (C) 2013 A. Pirillo and A. L. Catapano. This is an open access article distributed under the Creative Commons Attribution License, which permits unrestricted use, distribution, and reproduction in any medium, provided the original work is properly cited.

Lectin-like oxidized low density lipoprotein receptor-1 (LOX-1), the main oxidized low-density lipoprotein (OxLDL) in endothelial cells, is upregulated in atherosclerotic lesions and is involved in several cellular processes that regulate the pathogenesis of atherosclerosis. The LOX-1 expressed on the cell surface can be proteolytically cleaved and released in a soluble form (sLOX-1) in the circulation under pathological conditions. Serum levels of sLOX-1, in fact, are elevated at the early stages of acute coronary syndrome and are associated with coronary plaque vulnerability and with the presence of multiple complex coronary lesions. Moreover, in subjects with stable CAD, levels of serum sLOX-1 are associated with the presence of lesions in the proximal and mid-segments of the left anterior descending artery that are the most prone to rupture; in subjects undergoing percutaneous coronary intervention, baseline preprocedural serum sLOX-1 levels are associated with the incidence of periprocedural myocardial infarction. Altogether, these findings suggest that circulating levels of sLOX-1 might be a diagnostic and prognostic marker for atherosclerotic-related events.

\section{Introduction}

High levels of low density lipoprotein (LDL) represent a major risk factor for atherosclerosis, since the oxidation of LDL is a key process in the initiation and progression of atherosclerotic lesion development. Oxidized LDL (OxLDL) acts through the interaction with several scavenger receptors, expressed differentially on the surface of the cells of the arterial wall and inflammatory circulating cells involved in the atherosclerotic process. Among these receptors, lectinlike oxidized low-density lipoprotein receptor-1 (LOX-1) has been identified as the main endothelial receptor for OxLDL [1]; however, also macrophages and smooth muscle cells (SMCs) express LOX-1 [2]. Several proinflammatory stimuli, including tumor necrosis factor $\alpha(\mathrm{TNF} \alpha)$, C-reactive protein (CRP), interleukin-1 (IL-1), angiotensin II, and endothelin1 , and proatherogenic conditions (dyslipidemia, diabetes, hypertension) increase LOX-1 expression [3]. Through the interaction with LOX-1, OxLDL activates endothelial cells and induces endothelial dysfunction, SMC proliferation, and apoptosis; participates in the transformation of macrophages into foam cells, and induces platelet activation [3]. LOX1 is undetectable in healthy vessels but overexpressed in atherosclerotic lesions [2], where it actively participates in the initiation and progression of the disease, as demonstrated by LOX-1 deletion or overexpression studies in animal models $[4,5]$.

LOX-1 is a type II membrane protein belonging to the C-type lectin family [6]. It contains 4 domains: a short $\mathrm{N}$ terminal cytoplasmic domain, a transmembrane domain, a neck domain, and a lectin-like extracellular C-terminal domain which interacts with OxLDL [6]. The extracellular domain can be proteolytically cleaved and released as a soluble form (sLOX-1) [7]. The tumor necrosis factor- $\alpha$ converting enzyme (TACE/ADAM17) appears to be involved in the cleavage and release of growth factors, adhesion 


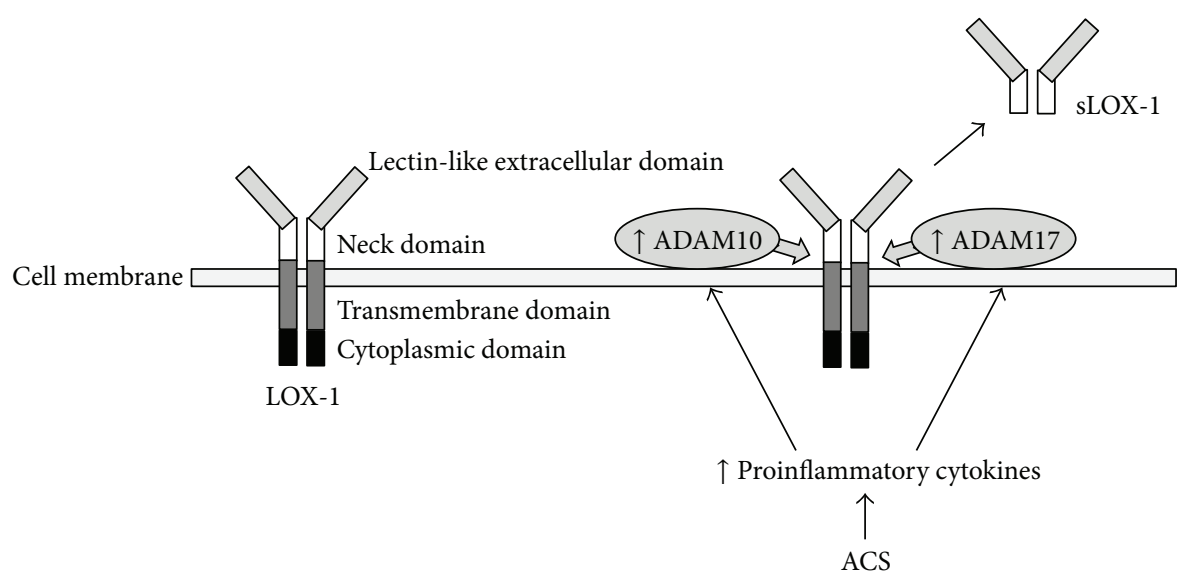

FIGURE 1: Schematic illustration of sLOX-1 release from cell membrane. Under acute inflammatory conditions, such as acute coronary syndrome (ACS), the increase of proinflammatory cytokines leads to protease activation and to subsequent sLOX-1 release.

molecules and receptors [8] and is believed to participate also in the sLOX-1 release [9] (Figure 1). In addition, the inflammatory factor IL-18 stimulates sLOX-1 cleavage from cell membrane, and ADAM10 (a disintegrin and metalloproteinase domain-containing protein 10) appears to be one of the proteases involved in this process [10] (Figure 1).

As elevated plasma levels of soluble receptors may reflect the increased expression of membrane-bound receptors and disease activities, circulating sLOX-1 has been suggested as a potential cardiovascular disease biomarker.

\section{2. sLOX-1 in Acute Coronary Syndrome}

Acute coronary syndrome (ACS), which derives from the rupture of atheromatous plaques followed by thrombus formation, is one of the major causes of death and morbidity in developed countries. Atherosclerotic plaques with abundant lipid-rich macrophages and activated SMCs appear to be more prone to rupture [11]; within these plaques, LOX-1 is highly expressed mainly by SMCs and macrophages [2], and participates in the induction of SMC apoptosis and the production of metalloproteases from endothelial cells [12], suggesting the involvement of LOX-1 in lesion destabilization. In addition, an enhanced protease activity within atherosclerotic lesions may increase sLOX-1 production.

Several studies have compared sLOX-1 levels with other biomarkers in patients with ACS, and it appears that sLOX1 may be a useful marker for early diagnosis of ACS. In fact, when evaluated in subjects undergoing coronary angiography (CAG), serum sLOX-1 levels were significantly higher in ACS patients compared to subjects without ACS (median, $2.91 \mathrm{ng} / \mathrm{mL}$ versus $<0.5 \mathrm{ng} / \mathrm{mL}$ ) [13]. High-sensitivity CRP (hs-CRP), an inflammation marker associated with ACS, was higher in ACS group and in non-ACS subjects with acute noncardiac illness but not in non-ACS subjects with intact coronary, controlled CHD, or ischemic CHD (Table 1) [13]. These observations suggest the possibility that, although LOX-1 expression is higher in atherosclerotic-related diseases and is increased by proinflammatory stimuli, sLOX-1 levels do not reflect only the presence of an atherosclerotic disease or an inflammatory status but rather the instability of an atherosclerotic plaque, thus discriminating ACS from other CAG groups. In agreement, both sLOX-1 and hs-CRP were associated with ACS (odds ratios 1.51, $P<0.001$ and 1.40, $P<$ 0.05 , resp.), but no significant correlation was found between sLOX-1 and hs-CRP in patients with ACS [13]. Interestingly, peak levels of sLOX-1 were observed on admission of or after percutaneous coronary intervention (PCI), while troponin T, a marker of cardiac injury, peaked around day 1 [13]; again, no correlation was found between sLOX-1 and troponin T [13], reinforcing the hypothesis that sLOX-1 is not a marker of cardiac damage but is an early diagnostic marker of ACS, as suggested by the finding that sLOX-1 level on admission showed almost the peak values in ACS patients. Thus, it seems that serum sLOX-1 levels start to increase before the onset of ACS.

Compared to subjects with stable coronary artery disease (CAD), patients with ACS show higher levels of sLOX-1 $(0.579 \mathrm{ng} / \mathrm{mL}$ versus $1.61 \mathrm{ng} / \mathrm{mL}, P<0.01)$ [14]; patients with ACS show also a significant positive correlation between sLOX-1 level increase and the number of complex lesions (Table 1) [14]. sLOX-1 levels were independently associated with the presence of multiple complex coronary lesions (odds ratio 1.967, $P<0.05$ ), thus suggesting the possibility that they might predict vulnerable plaques [14]. For patients who have no chance to undergo coronary angiography, sLOX-1 level measurement might thus help in identifying the presence of vulnerable atherosclerotic lesions.

Multiple complex lesions are often associated with adverse clinical outcomes in ACS patients [15]; as sLOX1 levels correlate with the presence of multiple complex lesions, it was hypothesized that sLOX-1 levels might predict the prognosis after ACS [16]. Thus, in ACS patients undergoing PCI, sLOX-1 levels (as well as other serum markers) were measured before the followup. Circulating sLOX-1 levels were higher in re-ACS patients as compared to the event-free ones $(6.60 \mathrm{ng} / \mathrm{mL}$ versus $2.54 \mathrm{ng} / \mathrm{mL}$ ) (Table 1 ), while no differences in hs-CRP or troponin $\mathrm{T}$ were found between the two groups [16]. ACS patients with the highest 
TABLE 1: Circulating sLOX-1 levels in acute coronary syndrome.

\begin{tabular}{|c|c|c|}
\hline Disease condition & Median (range); $P$ values & Reference \\
\hline $\begin{array}{l}\text { ACS } \\
\text { Non-ACS }\end{array}$ & $\begin{array}{l}2.91(<0.5-170) \mathrm{ng} / \mathrm{mL} ; P<0.05 \text { versus all groups } \\
\text { Intact coronary }<0.5(<0.5-1.3) \mathrm{ng} / \mathrm{mL} \\
\text { Controlled } \mathrm{CHD}<0.5(<0.5-3.4) \mathrm{ng} / \mathrm{mL} \\
\text { Ischemic CHD } 0.73(<0.5-14.0) \mathrm{ng} / \mathrm{mL}\end{array}$ & {$[13]$} \\
\hline $\begin{array}{l}\text { ACS } \\
\text { Stable CAD } \\
\text { ACS }\end{array}$ & $\begin{array}{l}1.61(0.941-2.264) \mathrm{ng} / \mathrm{mL} ; P<0.01 \text { versus stable CAD } \\
0.579(0.265-1.172) \mathrm{ng} / \mathrm{mL} \\
\text { No complex lesion: } 1.003(0.783-1.668) \mathrm{ng} / \mathrm{mL} \\
\text { One-complex lesion: } 1.456(0.923-2.124) \mathrm{ng} / \mathrm{mL} \\
\text { Multicomplex lesion: } 2.171(1.067-3.247) \mathrm{ng} / \mathrm{mL} \\
\end{array}$ & [14] \\
\hline $\mathrm{ACS}+\mathrm{PCI}$ & $\begin{array}{l}\text { Re-ACS: } 6.60 \mathrm{ng} / \mathrm{mL} ; P=0.0024 \\
\text { Event-free: } 2.54 \mathrm{ng} / \mathrm{mL}\end{array}$ & [16] \\
\hline $\begin{array}{l}\text { ACS with plaque rupture } \\
\text { ACS w/o plaque rupture } \\
\text { SAP }\end{array}$ & $\begin{array}{l}P<0.001 \text { versus ACS w/o plaque rupture and SAP } \\
P=0.002 \text { versus SAP }\end{array}$ & [17] \\
\hline $\begin{array}{l}\text { ACS } \\
\text { Non-ACS }\end{array}$ & $\begin{array}{l}1.13 \mathrm{ng} / \mathrm{mL} ; P<0.0001 \\
0.096 \mathrm{ng} / \mathrm{mL}\end{array}$ & {$[18]$} \\
\hline $\begin{array}{l}\text { STEMI } \\
\text { NSTEMI } \\
\text { Non-AMI }\end{array}$ & $\begin{array}{l}241.0 \mathrm{pg} / \mathrm{mL} ; P<0.001 \text { versus NSTEMI; } P=0.001 \text { versus non-AMI } \\
147.3 \mathrm{pg} / \mathrm{mL} ; P<0.001 \text { versus non-AMI } \\
64.3 \mathrm{pg} / \mathrm{mL}\end{array}$ & [19] \\
\hline $\begin{array}{l}\text { AAD } \\
\text { NSTEACS } \\
\text { Control }\end{array}$ & $\begin{array}{l}P<0.001 \text { versus NSTEACS; } P<0.001 \text { versus control } \\
P<0.001 \text { versus control }\end{array}$ & [23] \\
\hline
\end{tabular}

ACS: acute coronary syndrome; CAD: coronary artery disease; PCI: percutaneous coronary intervention; SAP: stable angina pectoris; STEMI: ST elevation myocardial infarction; NSTEMI: non-ST elevation myocardial infarction; AMI: acute myocardial infarction; AAD: acute aortic dissection; NSTEACS: non-ST elevation acute coronary syndrome.

sLOX-1 values had more frequent and earlier ACS recurrence or death [16]. These observations reinforce the hypothesis that serum sLOX-1 levels may be a biomarker for the vulnerability of atherosclerotic plaque and predict ACS recurrence in ACS patients.

In addition, it has been recently shown that sLOX-1 levels, but not hs-CRP or hs-TnT, can differentiate ACS with plaque rupture from those without [17]. Plasma sLOX-1 was significantly higher in ACS with plaque rupture subjects $(P<0.001)$ and in those without plaque rupture $(P=0.002)$ than in subjects with stable angina pectoris, and it was significantly higher in the plaque rupture group than in the nonrupture group $(P<0.001)$ (Table 1) [17]. Hs-CRP differed only between the plaque rupture group and the stable group $(P=0.048)$, while hs-TnT was significantly higher in both ACS groups $(P<0.001)$ than in stable patients and tended to be lower in the rupture group than in the nonrupture group $(P=0.055)$ [17]. sLOX-1, but not hs-CRP or hs-TnT, was significantly associated with plaque rupture and inversely correlated with the fibrous cap thickness [17], thus reflecting plaque vulnerability.

Comparison of sLOX-1 with Other Serum Cardiac Biomarkers. The diagnostic accuracy for ACS is essential to identify high-risk patients and differentiate them from non-ACS with similar chest pain and electrocardiogram anomalies; the evaluation of serum cardiac markers, which include cardiac troponins, cardiac kinase-MB (CK-MB), myoglobin, and heart-type fatty acid-binding protein (H-FABP), plays a crucial role in the diagnosis of ACS. Although TnT, HFABP, and sLOX-1 were all found to be higher in ACS patients than in non-ACS patients (Table 1), sLOX-1 revealed a higher sensitivity and specificity than TnT and H-FABP and could detect ACS in subjects with TnT values not significantly elevated [18]; in addition, in the ACS group, H-FABP values significantly correlated with TnT values, while sLOX-1 values did not correlate with TnT or H-FABP [18], indicating the independence of sLOX-1 from these two ACS biomarkers.

sLOX-1 represents a biomarker for plaque rupture or vulnerability, but not for myocardial damage; as plaque instability or rupture precedes cardiac damage in acute myocardial infarction, the sLOX-1 level increase is expected to precede the increase of biomarkers of cardiac injury. Accordingly, plasma sLOX-1 levels were significantly higher in subjects with acute myocardial infarction (AMI) than in non-AMI subjects $(P<0.001)$, and they were significantly higher in subjects with ST-elevation myocardial infarction (STEMI) than in the non-STEMI (NSTEMI) group $(P=0.001)$ (Table 1) [19]. In AMI patients, the number of diseased coronary vessels did not affect sLOX-1 levels [19]. sLOX-1 levels resulted elevated at the earliest stages of acute myocardial infarction ( 89 minutes from the symptom onset), persisted for $24 \mathrm{~h}$ after arrival at the emergency room, and declined to basal levels at 16 days after the onset of STEMI [19]. Other biomarkers peaked later (myoglobin and H-FABP after the termination of percutaneous coronary intervention, troponin $\mathrm{T}$ and CK-MB after $6 \mathrm{~h}$ ) and declined rapidly [19]. These findings, in agreement with previous data showing that the 
TABLE 2: Circulating sLOX-1 levels in coronary artery disease.

\begin{tabular}{|c|c|c|c|}
\hline Disease condition & Median (range) & $P$ values & Reference \\
\hline CAD & $\begin{array}{l}\text { 1-2 vessels: } 611(346-1313) \mathrm{pg} / \mathrm{mL} \\
\text { 3-4 vessels: } 2143(824-3201) \mathrm{pg} / \mathrm{mL}\end{array}$ & \multirow{2}{*}{$\begin{array}{l}P<0.05 \text { versus controls } \\
P<0.001 \text { versus controls; } P<0.05 \text { versus } 1-2 \text { vessels }\end{array}$} & \multirow{2}{*}[24]{} \\
\hline Healthy subjects & $268(111-767) \mathrm{pg} / \mathrm{mL}$ & & \\
\hline \multicolumn{4}{|l|}{ LAD artery } \\
\hline $\begin{array}{l}\text { (i) proximal/mid lesion } \\
\text { (ii) distal lesion }\end{array}$ & $\begin{array}{l}1.07 \pm 0.33 \mathrm{ng} / \mathrm{mL} \\
0.70 \pm 0.17 \mathrm{ng} / \mathrm{mL}\end{array}$ & $P<0.001$ & {$[25]$} \\
\hline ACS & $1.610(0.941-2.264) \mathrm{ng} / \mathrm{mL}$ & $P<0.01$ versus stable CAD & \\
\hline Stable CAD & $0.579(0.265-1.172) \mathrm{ng} / \mathrm{mL}$ & & \multirow[b]{2}{*}[14]{} \\
\hline Stable CAD & $\begin{array}{l}\text { Simple lesion: } 0.426(0.195-1.075) \mathrm{ng} / \mathrm{mL} \\
\text { Complex lesion: } 0.914(0.489-1.296) \mathrm{ng} / \mathrm{mL}\end{array}$ & $P<0.01$ versus simple lesion & \\
\hline Stable CAD + PCI & $\begin{array}{l}\text { MI: } 167 \pm 89 \mathrm{pg} / \mathrm{mL} \\
\text { Non-MI: } 99 \pm 68 \mathrm{pg} / \mathrm{mL}\end{array}$ & $P<0.001$ & {$[27]$} \\
\hline \multirow{6}{*}{ Stable CAD + PCI } & ISR & & \multirow{6}{*}[28]{} \\
\hline & Baseline $0.39(0.27-0.54) \mathrm{ng} / \mathrm{mL}$ & & \\
\hline & After PCI $0.85(0.63-0.98) \mathrm{ng} / \mathrm{mL}$ & $P<0.01$ versus baseline and non-ISR & \\
\hline & Non-ISR & & \\
\hline & Baseline $0.32(0.28-0.62) \mathrm{ng} / \mathrm{mL}$ & & \\
\hline & After PCI $0.45(0.36-0.84) \mathrm{ng} / \mathrm{mL}$ & $P<0.01$ versus baseline & \\
\hline
\end{tabular}

LAD: left anterior descending; ACS: acute coronary syndrome; CAD: coronary artery disease; PCI: percutaneous coronary intervention; MI: myocardial infarction; ISR: in-stent restenosis.

circulating sLOX-1 is a more sensitive and specific biomarker for ACS than TnT and H-FABP and can detect ACS in subjects with normal TnT levels [18], suggested that sLOX-1 may be a useful biomarker for diagnosing STEMI, although the evaluation of these sLOX-1 and hs-TnT in combination might improve the accuracy of ACS diagnosis [20].

Acute aortic dissection (AAD) is the most common lifethreatening disorder affecting the aorta and it has a high mortality rate if not correctly and rapidly diagnosed. D-dimer evaluation is the standard method to diagnose AAD [21], but it is not specific, as it is elevated also in acute ischemic events [22]. sLOX-1 levels were found to be significantly higher in AAD patients and in non-ST elevation ACS (NSTEACS) patients than in controls and significantly higher in AAD patients than in NSTEACS patients $(P<0.001)$ (Table 1$)$, while TnT levels were higher in NSTEACS patients than in AAD patients $(P=0.002)$ and controls $(P<0.001)$ [23]. These observations indicate the usefulness of sLOX-1 in combination with TnT to detect patients with AAD and distinguish them from those with NSTEACS.

\section{3. sLOX-1 in Stable CAD}

Serum sLOX-1 levels are associated with acute coronary syndrome; however, sLOX-1 appears to be a potential disease biomarker also in patients with stable CAD.

sLOX-1 as well as TNF $\alpha$, CRP, and IL- 6 levels were significantly higher in CAD patients than in controls [24]; sLOX-1 levels positively correlated with inflammatory markers including IL-6, TNF $\alpha$, and CRP, with TNF $\alpha$ being the only independent determinant of sLOX-1 levels [24]. The serum levels of sLOX-1 were higher in subjects with three or four vessels involved than in subjects with one or two vessels involved $(2143 \mathrm{pg} / \mathrm{mL}$ versus $611 \mathrm{pg} / \mathrm{mL}, P<0.05)$ (Table 2) [24], suggesting that circulating sLOX-1 levels might be related to CAD severity.

Atherosclerotic plaques of the proximal and mid segments of the left anterior descending (LAD) artery are the most prone to rupture. In subjects with stable CAD, levels of serum sLOX-1 were associated with these lesions [25]. In fact, patients with proximal/mid segment LAD lesions (as established by coronary angiograms) had significantly higher circulating sLOX-1 levels than those with distal segment LAD lesions $(1.07 \pm 0.33 \mathrm{ng} / \mathrm{mL}$ versus $0.70 \pm 0.17 \mathrm{ng} / \mathrm{mL}, P<$ 0.001) (Table 2) [25], suggesting that sLOX-1 levels may also represent a marker of atherosclerotic plaque localization in patients with stable CAD and may thus predict vulnerable plaques. Similarly to subjects with ACS, in patients with stable CAD, sLOX-1 levels were higher in subjects with complex lesions than in those with simple lesions $(0.914 \mathrm{ng} / \mathrm{mL}$ versus $0.426 \mathrm{ng} / \mathrm{mL}$ ) (Table 2) and were a significant and independent predictor of lesion complexity (odds ratio 1.964, $P<0.05)[14]$.

Percutaneous coronary intervention (PCI) is a common procedure for coronary revascularization in patients with stable CAD. Although the procedural complications and long-term outcomes have significantly improved, periprocedural myocardial infarction remains relatively frequent $(\sim$ $30 \%$ ) among patients undergoing PCI, with the increase of cardiac enzymes-indicative of myocardial injury [26]. In stable CAD, patients who manifested myocardial infarction related to PCI procedure, as confirmed by the increase of cardiac biomarkers, baseline preprocedural serum sLOX-1 levels were higher compared to subjects without myocardial 
damage $(167 \pm 89$ versus $99 \pm 68 \mathrm{pg} / \mathrm{mL}, P<0.001)$ (Table 2$)$ [27]. sLOX-1 levels also positively correlated with CK, CK$\mathrm{MB}$, and TnT [27], suggesting that sLOX-1 levels might be a biomarker to predict the risk of periprocedural myocardial damage in stable patients undergoing PCI. In addition, sLOX1 levels were evaluated before and after the procedure to verify whether it could predict in-stent restenosis (ISR) during the followup of patients with stable CAD who underwent successful primary PCI [28]. Baseline sLOX-1 levels were comparable; PCI significantly increased serum sLOX-1 levels at $24 \mathrm{~h}$ after stent implantation in all patients [28], which might reflect a high expression of LOX-1 at the site of stenting. However, the increase was more robust in patients with ISR at 6-month followup (Table 2), and postprocedural levels are significantly associated with the risk and severity of ISR after stent implantation [28]. This suggests that stent implantation induces plaque disruption and upregulation of LOX-1 in several cell types, including platelets, resulting in SMC migration, platelet aggregation, and inflammatory cell recruitment leading to restenosis.

\section{4. sLOX-1 in Metabolic Disorders}

Circulating levels of sLOX-1 are significantly higher in metabolic disorders including obesity [29] and type 2 diabetes mellitus [30].

In obese postmenopausal women, sLOX-1 levels were significantly increased compared to both lean $(+79 \%)$ or overweight women $(+44 \%)$ [29], which may suggest an increased LOX-1 expression in adipose tissue. Plasma sLOX1 levels were positively associated with body weight, BMI, and total body fat [29]. Weight loss resulted in a significant decrease of sLOX-1 levels; women with the highest sLOX1 levels at baseline had the greatest reductions in sLOX-1 with weight loss $(r=-0.80, P<0.0001)$ [31]. Similarly, in overweight men, serum sLOX-1 levels decreased significantly with body weight reduction; changes in serum sLOX-1 levels positively correlated also with changes in body mass index (BMI), total cholesterol, hs-CRP, leptin, and TNF $\alpha$ [32], suggesting that LOX-1 induction may be related to adipocyte metabolism, inflammation, and immune response associated with obesity.

The metabolic syndrome (MetS) constitutes a complex disorder combining obesity, dyslipidemia, hyperglycemia, and hypertension, associated with an increased risk of cardiovascular diseases, especially CAD. In subjects with MetS, patients with CAD showed a higher level of serum sLOX1 compared to subjects without CAD $(0.925 \mathrm{ng} / \mathrm{mL}$ versus $0.207 \mathrm{ng} / \mathrm{mL}, P<0.01$ ) [33]; among the variables that showed an association with the presence of CAD (sLOX1, age, gender, and BMI), sLOX-1 represented a relevant independent predictor of angiographic CAD [33]. In addition, in patients with MetS and CAD, serum sLOX-1 levels significantly correlated with the angiographically determined severity of CAD [33], in agreement with previous findings [24]. sLOX-1 levels might thus be used as a biomarker for the detection and risk assessment of CAD in subjects with MetS.

Patients with type 2 diabetes, which is associated with increased oxidative stress and subclinical inflammation, had serum sLOX-1 levels significantly higher compared to nondiabetic subjects (111.4 ng/mL versus $102.5 \mathrm{ng} / \mathrm{mL}$, $P<0.01)$ [30]. Both glucose and advanced glucose endproducts (AGEs) were significant determinants of LOX-1 expression, as glycemic control, which induces glucose and AGE lowering, leads to a reduction of circulating sLOX-1 [30].

Peripheral artery disease (PAD) is characterized by an atherosclerotic occlusive disease of the lower extremities, and diabetes and smoking are the strongest risk factors for PAD [34]. In type 2 diabetic patients, serum sLOX-1 levels were significantly higher in subjects with PAD than in those without PAD $(490.3 \pm 299.3 \mathrm{pg} / \mathrm{mL}$ versus $366.9 \pm 258.0 \mathrm{pg} / \mathrm{mL}$, $P<0.05)$ [35]. sLOX-1 levels were also inversely correlated with ankle-brachial index (ABI) $(r=-0.197, P<0.0001)$ and were associated with PAD [35], which suggests that serum sLOX-1 concentration could be a marker for PAD in patients with type 2 diabetes.

\section{Conclusions}

LOX-1 expression is upregulated under several pathological conditions related to atherosclerosis. As a membrane-bound protein with a single $\mathrm{C}$-terminal domain, it can be cleaved and released as a soluble form in the circulation, thus allowing its measurement in patients. sLOX-1 increases in plasma or serum of patients with ACS or with CAD compared to control subjects and, when combined with other serum biomarker levels, might have the potential to increase the diagnosis accuracy of acute coronary syndromes or to predict disease progression or the risk of future cardiovascular events.

\section{References}

[1] T. Sawamura, N. Kume, T. Aoyama et al., "An endothelial receptor for oxidized low-density lipoprotein," Nature, vol. 386, no. 6620, pp. 73-77, 1997.

[2] H. Kataoka, N. Kume, S. Miyamoto et al., "Expression of lectinlike oxidized low-density lipoprotein receptor-1 in human atherosclerotic lesions," Circulation, vol. 99, no. 24, pp. 31103117, 1999.

[3] S. Xu, S. Ogura, J. Chen, P. J. Little, J. Moss, and P. Liu, "LOX1 in atherosclerosis: biological functions and pharmacological modifiers," Cellular and Molecular Life Sciences, vol. 70, pp. 2859-2872, 2013.

[4] J. L. Mehta, N. Sanada, C. P. Hu et al., "Deletion of LOX1 reduces atherogenesis in LDLR knockout mice fed high cholesterol diet," Circulation Research, vol. 100, no. 11, pp. 16341642, 2007.

[5] K. Inoue, Y. Arai, H. Kurihara, T. Kita, and T. Sawamura, "Overexpression of lectin-like oxidized low-density lipoprotein receptor-1 induces intramyocardial vasculopathy in apolipoprotein E-null mice," Circulation Research, vol. 97, no. 2, pp. 176$184,2005$.

[6] T. Navarra, S. Del Turco, S. Berti, and G. Basta, "The lectinlike oxidized low-density lipoprotein receptor-1 and its soluble form: cardiovascular implications," Journal of Atherosclerosis and Thrombosis, vol. 17, no. 4, pp. 317-331, 2010.

[7] T. Murase, N. Kume, H. Kataoka et al., "Identification of soluble forms of lectin-like oxidized LDL receptor-1," Arteriosclerosis, 
Thrombosis, and Vascular Biology, vol. 20, no. 3, pp. 715-720, 2000.

[8] D. Dreymueller, J. Pruessmeyer, E. Groth, and A. Ludwig, "The role of ADAM-mediated shedding in vascular biology," European Journal of Cell Biology, vol. 91, no. 6-7, pp. 472-485, 2012.

[9] X. Q. Zhao, M. W. Zhang, F. Wang et al., "CRP enhances soluble LOX-1 release from macrophages by activating TNF- $\alpha$ converting enzyme," Journal of Lipid Research, vol. 52, no. 5, pp. 923-933, 2011.

[10] H. Mitsuoka, N. Kume, K. Hayashida et al., "Interleukin 18 stimulates release of soluble lectin-like oxidized LDL receptor-1 (sLOX-1)," Atherosclerosis, vol. 202, no. 1, pp. 176-182, 2009.

[11] A. C. van der Wal and A. E. Becker, "Atherosclerotic plaque rupture-pathologic basis of plaque stability and instability," Cardiovascular Research, vol. 41, no. 2, pp. 334-344, 1999.

[12] S. Ishino, T. Mukai, N. Kume et al., "Lectin-like oxidized LDL receptor-1 (LOX-1) expression is associated with atherosclerotic plaque instability-analysis in hypercholesterolemic rabbits," Atherosclerosis, vol. 195, no. 1, pp. 48-56, 2007.

[13] K. Hayashida, N. Kume, T. Murase et al., "Serum soluble lectin-like oxidized low-density lipoprotein receptor-1 levels are elevated in acute coronary syndrome a novel marker for early diagnosis," Circulation, vol. 112, no. 6, pp. 812-818, 2005.

[14] Z. W. Zhao, X. L. Zhu, Y. K. Luo, C. G. Lin, and L. L. Chen, "Circulating soluble lectin-like oxidized low-density lipoprotein receptor-1 levels are associated with angiographic coronary lesion complexity in patients with coronary artery disease," Clinical Cardiology, vol. 34, no. 3, pp. 172-177, 2011.

[15] J. A. Goldstein, D. Demetriou, C. L. Grines, M. Pica, M. Shoukfeh, and W. W. O’Neill, "Multiple complex coronary plaques in patients with acute myocardial infarction," The New England Journal of Medicine, vol. 343, no. 13, pp. 915-922, 2000.

[16] N. Kume, H. Mitsuoka, K. Hayashida, M. Tanaka, and T. Kita, "Soluble lectin-like oxidized low-density lipoprotein receptor-1 predicts prognosis after acute coronary syndrome: a pilot study," Circulation Journal, vol. 74, no. 7, pp. 1399-1404, 2010.

[17] N. Kobayashi, M. Takano, N. Hata et al., "Soluble lectin-like oxidized LDL receptor-1 (sLOX-1) as a valuable diagnostic marker for rupture of thin-cap fibroatheroma: verification by optical coherence tomography," International Journal of Cardiology, 2013.

[18] N. Kume, H. Mitsuoka, K. Hayashida, M. Tanaka, G. Kominami, and T. Kita, "Soluble lectin-like oxidized LDL receptor-1 (sLOX1) as a sensitive and specific biomarker for acute coronary syndrome-comparison with other biomarkers," Journal of Cardiology, vol. 56, no. 2, pp. 159-165, 2010.

[19] N. Kobayashi, N. Hata, N. Kume et al., "Soluble lectin-like oxidized low-density lipoprotein receptor-1 as an early biomarker for ST elevation myocardial infarction: time-dependent comparison with other biomarkers," Circulation Journal, vol. 75, no. 6, pp. 1433-1439, 2011.

[20] N. Kobayashi, N. Hata, N. Kume et al., "Soluble lectin-like oxidized LDL receptor-1 and High-sensitivity troponin $\mathrm{T}$ as diagnostic biomarkers for acute coronary syndrome: improved values with combination usage in emergency rooms," Circulation Journal, vol. 75, no. 12, pp. 2862-2871, 2011.

[21] T. Suzuki, A. Distante, A. Zizza et al., "Diagnosis of acute aortic dissection by $\mathrm{D}$-dimer: the international registry of acute aortic dissection substudy on biomarkers (IRAD-Bio) experience," Circulation, vol. 119, no. 20, pp. 2702-2707, 2009.
[22] A. Bayes-Genis, J. Mateo, M. Santaló et al., "D-dimer is an early diagnostic marker of coronary ischemia in patients with chest pain," The American Heart Journal, vol. 140, no. 3, pp. 379-384, 2000.

[23] N. Kobayashi, N. Hata, N. Kume et al., "Detection of acute aortic dissection by extremely high soluble lectin-like oxidized LDL receptor-1 (sLOX-1) and low troponin T levels in blood," International Journal of Cardiology, vol. 165, pp. 557-559, 2013.

[24] V. Lubrano, S. Del Turco, G. Nicolini, P. Di Cecco, and G. Basta, "Circulating levels of lectin-like oxidized low-density lipoprotein receptor-1 are associated with inflammatory markers," Lipids, vol. 43, no. 10, pp. 945-950, 2008.

[25] M. Balin, A. Celik, and M. A. Kobat, "Circulating soluble lectin-like oxidized low-density lipoprotein receptor-1 levels are associated with proximal/middle segment of the LAD lesions in patients with stable coronary artery disease," Clinical Research in Cardiology, vol. 101, no. 4, pp. 247-253, 2012.

[26] G. G. Babu, J. M. Walker, D. M. Yellon, and D. J. Hausenloy, "Peri-procedural myocardial injury during percutaneous coronary intervention: an important target for cardioprotection," European Heart Journal, vol. 32, no. 1, pp. 23-31, 2011.

[27] M. Balin, A. Celik, M. A. Kobat, and A. Baydas, "Circulating soluble lectin-like oxidized low-density lipoprotein receptor1 levels predict percutaneous coronary intervention-related periprocedural myocardial infarction in stable patients undergoing elective native single-vessel PCI," Journal of Thrombosis and Thrombolysis, vol. 34, pp. 483-490, 2012.

[28] B. Li, L. H. Zhang, X. G. Yang, Y. Liu, X. T. Liu, and Y. G. Ren, "Postprocedural serum sLOX-1 levels are associated with coronary in-stent restenosis in patients with stable coronary artery disease," Coronary Artery Disease, vol. 22, no. 4, pp. 259263, 2011.

[29] T. E. Brinkley, N. Kume, H. Mitsuoka, D. A. Phares, and J. M. Hagberg, "Elevated soluble lectin-like oxidized LDL receptor-1 (sLOX-1) levels in obese postmenopausal women," Obesity, vol. 16, no. 6, pp. 1454-1456, 2008.

[30] K. C. B. Tan, S. W. M. Shiu, Y. Wong, L. Leng, and R. Bucala, "Soluble lectin-like oxidized low density lipoprotein receptor-1 in type 2 diabetes mellitus," Journal of Lipid Research, vol. 49, no. 7, pp. 1438-1444, 2008.

[31] T. E. Brinkley, X. Wang, N. Kume, H. Mitsuoka, and B. J. Nicklas, "Caloric restriction, aerobic exercise training and soluble lectinlike oxidized LDL receptor-1 levels in overweight and obese post-menopausal women," International Journal of Obesity, vol. 35, no. 6, pp. 793-799, 2011.

[32] Y. Nomata, N. Kume, H. Sasai et al., "Weight reduction can decrease circulating soluble lectin-like oxidized low-density lipoprotein receptor-1 levels in overweight middle-aged men," Metabolism, vol. 58, no. 9, pp. 1209-1214, 2009.

[33] B. Li, L. H. Zhang, X. G. Yang, X. T. Liu, and Y. G. Ren, "Serum sLOX-1 levels are associated with the presence and severity of angiographic coronary artery disease in patients with metabolic syndrome," Clinical and Investigative Medicine, vol. 33, no. 6, pp. E398-E404, 2010.

[34] American Diabetes Association, "Peripheral arterial disease in people with diabetes," Diabetes Care, vol. 26, no. 12, pp. 33333341, 2003.

[35] M. Fukui, M. Tanaka, T. Senmaru et al., "LOX-1 is a novel marker for peripheral artery disease in patients with type 2 diabetes," Metabolism, vol. 62, no. 7, pp. 935-938, 2013. 


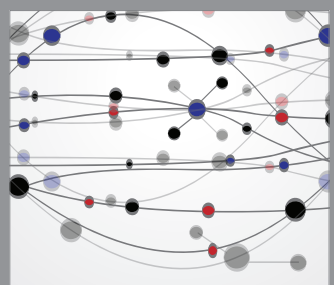

The Scientific World Journal
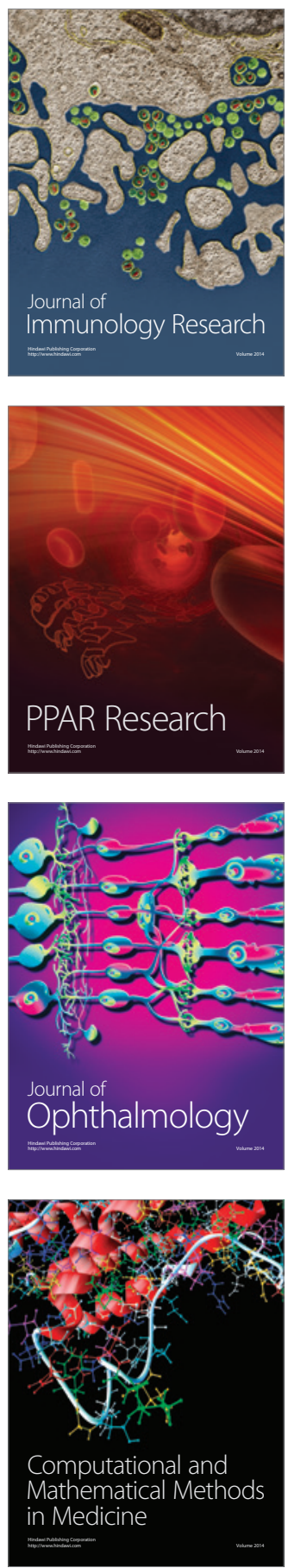

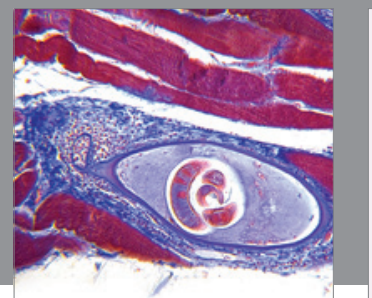

Gastroenterology

Research and Practice
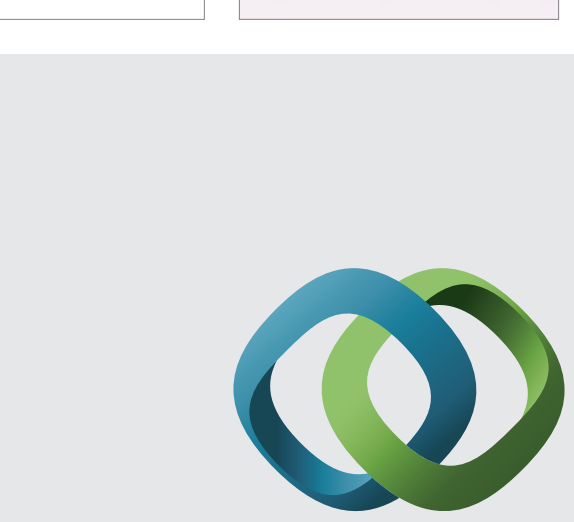

\section{Hindawi}

Submit your manuscripts at

http://www.hindawi.com
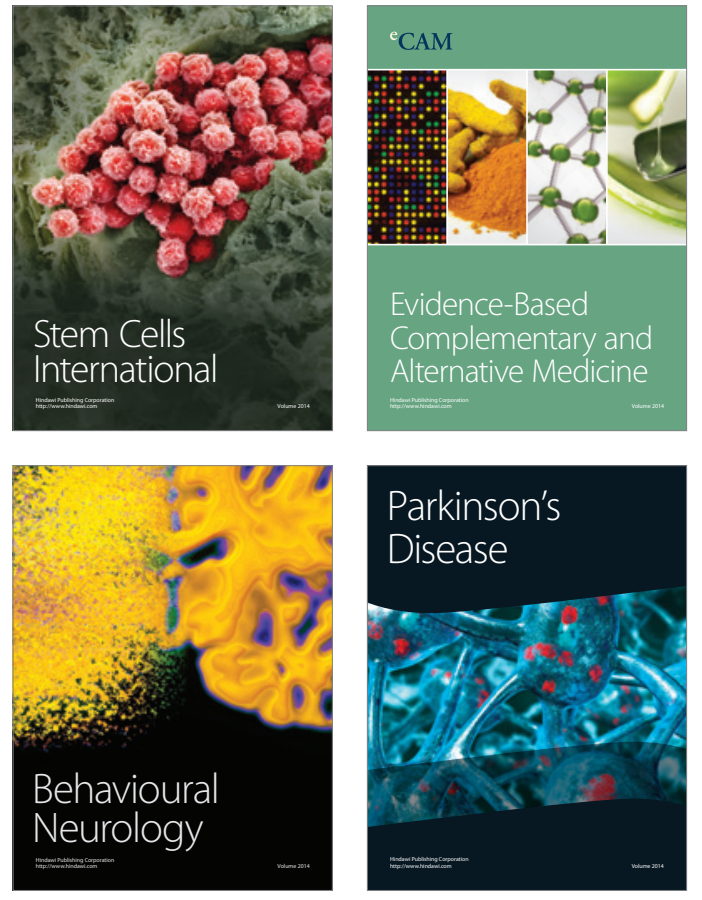
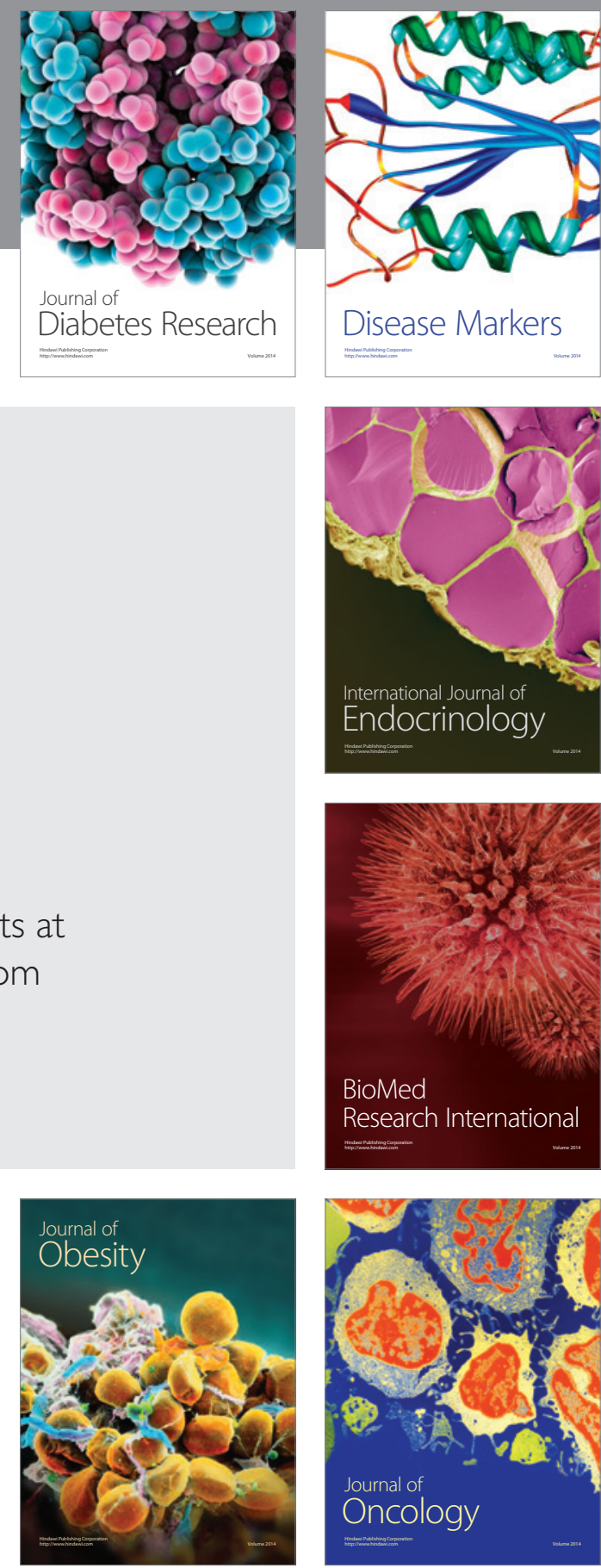

Disease Markers
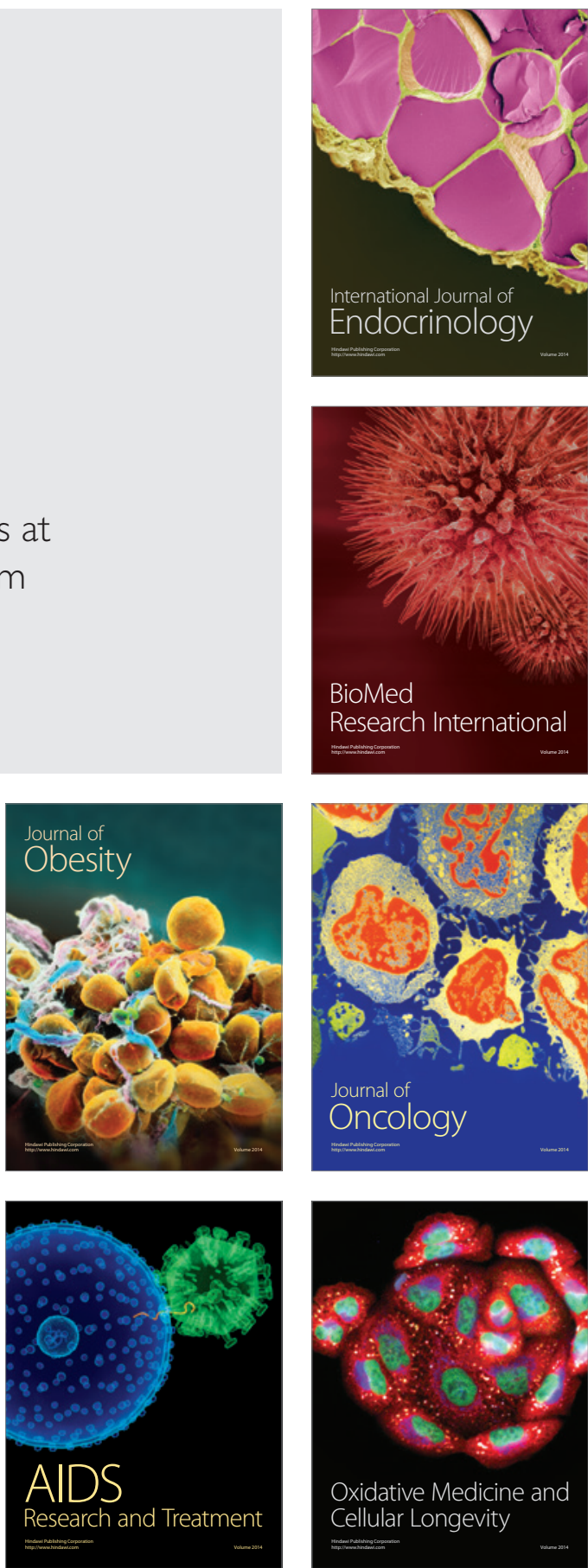